
\title{
28 Research Soure \\ Innovative Solutions for Disaster Early Warning and Alert Systems: A Literary Review
}

Vladimir M. Cvetković ( $\sim$ vladimirkpa@gmail.com )

Faculty of Security Studies, University of Belgrade, Gospodara Vučića 50, 11040 Belgrade, Serbia https://orcid.org/0000-0002-3450-0658

\section{Systematic Review}

Keywords: disasters, early warning, alert system, innovative solutions, DAREnet, literary review

Posted Date: September 21st, 2021

DOl: https://doi.org/10.21203/rs.3.rs-923237/v1

License: (c) (i) This work is licensed under a Creative Commons Attribution 4.0 International License. Read Full License 


\section{Abstract}

In different parts of the world, decision-makers and risk managers use specific and particularly complex disaster early warning and alert systems to protect people and their material goods from the harmful effects of various disasters in a timely, efficient and appropriate manner. However, concerning the level of scientific-technological and economic development of certain countries, such systems can differ in the many characteristics that make them more efficient in specific situations. Guided by this, the subject of the paper is reflected in the systematic identification, analysis, and classification of the best innovative solutions of early warning systems regarding their usability and efficiency. To find appropriate innovative solutions, it was performed a search of different electronic databases. The findings of this review showed that there is a huge potential for innovative solutions in the field of disaster early warning and alert systems.

\section{Introduction}

Around the world, national and regional organizations are developing technical systems to detect potential natural hazards (Fujita \& Shaw, 2019; Guo \& Kapucu, 2019; Ocal, 2019) as timely and easily as possible, then pass on such information to citizens and enable them to protect themselves on time. Many communication tools, such as short message service (SMS), email, radio, TV, and online service, are now accessible for warning distribution (Alias et al., 2020; Aloudat \& Michael, 2011; Chen, Zhu, Ni, \& Su, 2020; Grasso \& Singh, 2011; Mills, Chen, Lee, \& Raghav Rao, 2009; Sharma et al., 2015). In literature, there is a great deal of empirical evidence that the systems mentioned are successful in terms of decreasing human fatalities and saving property (Kull, Mechler, \& Hochrainer-Stigler, 2013; Mechler, 2016; Rai, van den Homberg, Ghimire, \& McQuistan, 2020) and essential features of civil protections (Alfieri, Salamon, Pappenberger, Wetterhall, \& Thielen, 2012).

Certainly, the most frequently used technologies for warning the public are sirens (Bubar et al., 2020; Kuligowski, Kuligowski, \& Doermann, 2018; Perera et al., 2020; Piciullo, Calvello, \& Cepeda, 2018) that are publicly announced, electronic media and the staff of competent institutions that go on the streets and inform the citizens by using appropriate speakers or megaphones (Sorensen, 2000). All the mentioned ways of informing the citizens have their advantages and disadvantages, as well as innovative improvements or alternative replacements. Early warning systems had their origins in the 1980s when famines in Sudan and Ethiopia prompted the need to predict and prevent future food insecurity (Alcántara-Ayala \& Oliver-Smith, 2019; Kim \& Guha-Sapir, 2012). Early warning systems designed for volcano, earthquake, tsunami, and flood risks may appear inadequate when dealing with illnesses like COVID-19 (Cvetković et al., 2020; Fearnley \& Dixon, 2020; Öcal, Cvetković, Baytiyeh, Tedim, \& Zečević, 2020). For these reasons, continuous improvement of early warning systems (LaBrecque, Rundle, \& Bawden, 2019; Perera et al., 2020; Yang, Zhang, Wang, \& Tang, 2018) is needed to respond to all the natural and anthropogenic risks faced by the community. In the future, cell phones might be used to communicate outlooks and warnings to rural locations that lack communications infrastructure, as could 
satellite-based broadcasts of danger warnings to remote areas (Glantz, 2003; Indrasari, Iswanto, \& Andayani, 2018; Toya \& Skidmore, 2018).

In practice, alert, detection, prevention, monitoring, and warning systems, have unambiguously been referred to as early warning systems (Sättele, Bründl, \& Straub, 2016). Excellent and highly reliable early warning systems can detect various types of natural hazards and never produce a false alarm (Intrieri, Gigli, Mugnai, Fanti, \& Casagli, 2012). The United Nations Office for Disaster Risk Reduction (UNISDR, 2012) defines a warning system as a set of capabilities needed for the timely and meaningful generation and dissemination of alert information to individuals, communities, and organizations at risk for optimal preparedness and response and at the appropriate time to reduce the likelihood of injury and death (International Strategy for Disaster Reduction, 2004). Basher (2006, p. 2171) defined early warning systems as a linear set of connections from observations through warning generation and transmittal to the user. The Hyogo Action Framework has also focused on identifying, evaluating, monitoring, and increasing early warnings in disaster risks (UNISDR, 2005). High false alarm rates are a major issue in the operation of these systems, as they can weaken public trust, promote distrust, dilute the impact of alerts, and diminish the credibility of future warnings. Early warning system failures frequently arise in the communication and preparation aspects (Basher, 2006; Sorensen, 2000). Krzhizhanovskaya et al. (2011, p. 107) highlight that the introduction of an early warning system requires the development of a range of innovations and disciplines of expertise, including the construction, implementation, and technical maintenance of flood protection system sensor equipment; sensor data transport, filtering, and analytics software; dyke stability analysis, dike collapse prediction, prospective dynamic flood models and evacuation technique optimizations are all conceivable with computer models and simulation elements; technological advancements for interactive visualization; develop a decision-making support system to assist public authorities and people in selecting and reacting to optimum flood control methods; remote connection over Internet or customized remote access to early warning and decisions support systems, etc.

Taking into account the above, the aim of this paper is a scientific description and systematic identification, analysis, and classification of the best innovative solutions of early warning systems. Also, the best world solutions in that regard are analyzed to see the best systems.

\section{Methods}

\section{Aim and search strategy}

The purpose of this review was systematic identification, analysis, and classification of the best innovative solutions regarding early warning and alert systems. To find appropriate research, a search of an electronic database was performed. Web of Science, Scopus, Google scholar, DAREnet Knowledge Base, was the main source used for literature searches (Cvetkovic \& Martinović, 2020). The studies were incorporated into the EndNote program after searching all databases.

\section{Inclusion and exclusion criteria}


Articles were considered for review if the objective of the research was some kind of innovative solutions for early warning and alert systems. Furthermore, articles were included for review if they met the following criteria: (1) peer-reviewed, (2) useful and used by practitioners, and (3) related to these early warning systems, alert system, warnings, monitoring and observation, disaster (flood, earthquake, tsunami, landslides, drought, etc.), forecasting, (4) related to subtopics as models, framework, technical equipment, standardization, evacuation. Articles that included some unusable solution, insufficiently tested, scientifically unproven were excluded from the review.

\section{Search outcomes}

The initial search resulted in 250 papers and this number diminished to 70 after a review of titles and abstracts found that 180 articles had no relevance to the objectives of the review. A full-text reading of the remaining articles resulted in 50 studies that were considered appropriate for review.

\section{Types Of Early Warning Systems For Natural Hazards}

There are traditional and advanced systems of early warning and alert systems in the world. Traditional ones usually consist of three phases: a) monitoring of precursors; b) forecasting of a probable event; $c$ ) the notification of a warning or an alert should an event of disasters take place (de León, Bogardi, Dannenmann, \& Basher, 2006). Early warning systems differ strongly in their monitoring strategies and two main monitoring strategies can be distinguished (Sättele, 2015). The data contents of the monitored data are high, but the related lead times are low if the early warning systems monitor existing continuous risk event characteristics. If the early warning systems tracks precursors before the commencement of a hazardous event the data contents are decreased, but, the lead time is increased. Because of that, they vary in their spatial dimensions, lead time, design, and associated degree of automation. Fakhruddin and Chivakidakarn (2014) identify four elements for early warning systems to be effective that research has consistently found: (1) active input from vulnerable groups; (2) continuing public education and awareness initiatives; (3) multi-faceted delivery of the messages and the alerts.

The literature also promotes the fourth phase, which refers to indicating the beginning of disaster response activities after a warning has been issued. The four elements of people-centered early warning systems: risk knowledge; dissemination; warning service; response capability (de León et al., 2006). Sophisticated classification for early warning systems could not be found in the literature and several institutions developed definitions for the terms alarm (Villagrán de León, Pruessner, \& Breedlove, 2013). Sättele's (2015) novel approach classifies early warning systems into alarm systems, warning systems, and forecasting systems. Also, in literature, there is a dichotomy between current early warning systems, which either mainly focus on the hazard component of disaster risk (Rogers \& Tsirkunov, 2011), or follow a people-centered approach (Thomalla \& Larsen, 2010), including the dissemination of information for the people to react to a given hazard. Concerning the occurrence type of a natural hazard process, three monitoring strategies can be distinguished (Sättele, 2015): precursors of processes that evolve slowly are monitored; precursors of processes that are triggered spontaneously are monitored; process parameters of processes that are triggered spontaneously are monitored. 
It should be noted that the designs of early warning systems differ depending on the disaster for which they are designed. For example, the early warning system for nuclear preparation is based on the Arduino software, a GPRS shield, and radiofrequency technology to send ambient radiation measuring results and meteorological data (Farid, Prawito, Susila, \& Yuniarto, 2017). The aforementioned early warning system comprises continuous monitoring of ambient radiation and an alarm mechanism. In addition, the system was intended to continually monitor the gamma air dosage rate in the facility's environment. The dependability of sensors, data transmission equipment, and data processing mechanisms at the Server all indicate environmental radiation online monitoring (Farid et al. 2017). Khankeh, Hosseini, Farrokhi, Hosseini, and Amanat (2019) found that there has been no systematic evaluation of early warning system models, structures, and components, and there have been some attempts to fully analyze early warning system models and components. One of the recognized innovations is stochastic early warning system design, which uses a risk measure as a reference variable to allow integration of the many impacts collected by monitoring devices (Medina-Cetina \& Nadim, 2008). As mentioned, the risk measure not only acts as a logical index for determining warning levels but also integrates EWS into a decisionmaking framework.

\section{Practice And Solutions In Warning Systems}

In different countries, certain systems are applied that specialize in certain types of hazards, but on the other hand, have their advantages and disadvantages. In Italy, there is an operational warning system for shallow landslides that monitors the whole region and displays real-time results on a graphical interface via a dedicated software module called SMART - shallow landslides movements announced by rainfall thresholds (calibrated through a database of 160 landslides with hourly information of gauged precipitation and time of triggering) (Alfieri et al., 2012; Tiranti \& Rabuffetti, 2010).

Multi-hazard Early Warnings, applied in China, includes multi-agency coordination, cooperation, and participation in disaster prevention mechanisms (Rogers \& Tsirkunov, 2011). Also, the China Meteorological Administration (CMA), for example, issues fourteen categories of warning signals: tropical cyclones, heavy rain, heavy snow, cold surges, strong wind, dust, heatwaves, droughts, thunder and lightning, hail, frost, heavy fog, haze, icy roads (Tang \& Zou, 2009). Worldwide, national Meteorological and Hydrological Services in charge of hydrometeorological-related early warning systems continuously conduct systematic monitoring and observation of hydrometeorological indicators, provide various data in real-time, analyze hazards and perform mapping as well as hazard forecasting (Rogers \& Tsirkunov, 2011).

A group of German scientists developed a concept for a tsunami early warning system for the region (German-Indonesian Tsunami Early Warning System) which presents complete new technologies and scientific concepts to reduce early-warning times down to 5-10 min with the integration of near real-time GPS deformation monitoring as well as new modeling techniques and decision supporting procedures (Rudloff, Lauterjung, Münch, \& Tinti, 2009). In Finland, the monitoring unit of the national forecasting system includes measuring stations and manual measurements for precipitation, water level, discharge, 
run and snow water equivalent, ice thickness, water temperature (SKYE, 2013). In England, more than 200 stations measure meteorological parameters, including air temperature, atmospheric pressure, precipitation, wind speed and direction, humidity, cloud height, and visibility. In addition, technologies such as weather satellites, balloons, and aircraft measurements are applied (Legg \& Mylne, 2004). In Switzerland, alarms (acoustic or optical signals) are directly issued to endangered persons or the public, in contrast to warnings that are issued to inform responsible authorities about potential risks (Martina Sättele, 2015).

In Serbia, according to the current Law on Disaster Risk Reduction and Emergency Management (Official Gazette of RS, No. 87/2018), the public alarm system consists of appropriate acoustic sources (sirens), devices for transmitting and receiving signals for remote control of sirens, portable roads and other equipment and specialized civil protection units for alerting. It is also prescribed that local governments perform procurement, installation, and maintenance following their risk assessments, acoustic studies, technical standards, etc. It is important to mention that local governments have a legal obligation to complete acoustic studies within 3 years, and if they do not have a remote activation system, they must have specialized civil protection units for alerting. The mentioned system is managed by the Ministry of Internal Affairs. It is important to mention that sirens were installed in Serbia almost 50 years ago, and it can be said that their functionality is largely questionable. Also, even after 11 years of the stated intention to introduce the universality of the system "number 112 for emergency calls" which was supposed to provide coordinated, rapid, and efficient intervention and assistance in disasters, in full compliance with standards and practices present in European Union countries is not yet functional (Cvetković, 2020).

In the late 1940s, the United States began to build its federal early warning system as part of a postwar drive to invest in decreasing the effect of tropical cyclones, floods, storms, drought, tsunamis, and other dangers that endangered its population (Buan \& Diamond, 2012). All of this contributed to the development of the National Response Framework, the Incident Command System, the multi-channel Emergency Alert System, and federal, state, and local policies that encouraged increased hazard awareness, risk mitigation, and disaster preparation (Buan \& Diamond, 2012). Integration of MultiChannel Disaster Alert Systems include three main elements (Klafft \& Ziegler, 2014, p. 2): a) one or more instances of alert message producers, i.e. distinct front-ends used by various authorities for creating and defining alert messages; an alert message repository as a central storage location for alerts from multiple, dispersed warning systems; c) dissemination channels - the messages repository's specified interface allows for the inclusion of new alert message distribution systems as they become available.

The Russian early-warning system, which was developed to provide Soviet strategic forces with information in the event of a nuclear disaster, has two main components: a network of early-warning radars and a space-based early-warning system with satellites in highly elliptical and geosynchronous orbits (Podvig, 2002). Russia has over 90 satellites that were initiated between 1972 and 2003 to form the early warning system's satellite constellation (Paleologue, 2005). It is significant to mention that there are different platforms, and one of them is the first operational runoff forecasting system in Russia which is open forecast based only on open-source software and data-GR4J hydrological model, ERA-Interim 
meteorological reanalysis, and ICON deterministic short-range meteorological forecasts (Ayzel et al., 2019).

The Japanese government launched a new countrywide early-warning system for landslide disasters in 2005 and the system's core technique is to establish criteria for debris flow and slope collapse events based on multiple rainfall indicators in each $5-\mathrm{km}$ grid mesh encompassing all of Japan (Osanai, Shimizu, Kuramoto, Kojima, \& Noro, 2010). Earthquake early-warning systems, first introduced in Japan, have facilitated the communication of very short-term warnings that earthquake movements from earthquakes will arrive in seconds to tens of seconds. Currently, the national system exists only in Japan, but regional systems are becoming available in many earthquake-prone countries, including the United States. Another means of earthquake prediction is the operational prediction of earthquakes based on the occurrence of seismic activity of various types, which increases the short-term probability that additional earthquakes, including harmful earthquakes, could occur in a few hours to a few days (Goltz \& Roeloffs, 2020).

As part of the UrbanFlood FP7 project, Krzhizhanovskaya et al. (2011) created a prototype of an early flood warning system. Sensor networks are deployed in flood barriers (dikes, embankments, etc.). The system analyzes sensor signal anomalies, estimates dike failure probabilities, and simulates probable cases of dike breaking and flood propagation, among other things. An interactive decision support system uses all the essential information and simulation results to enable dike managers and city officials to make educated decisions in disaster situations and normal dike inspections. A considerable number of initiatives aiming at developing better and "smarter" flood protection systems have been completed in recent years (Akhtar, Corzo, van Andel, \& Jonoski; Artan, Restrepo, Asante, \& Verdin; Gouldby, Krzhizhanovskaya, \& Simm, 2010; Pengel et al., 2013; Thennavan et al, 2020; Chakma et al., 2021): DAREnet project (Cvetkovic \& Martinović, 2020); the FLOODsite project - a set of efficient models essential for flood risk analysis as well as the management methodologies (Morris, Kortenhaus, \& Visser, 2009); Delft-FEWS - a hydrological forecast and warning system (Gijsbers); FloodControl 2015 - an advanced forecasting and decision support system (Pengel et al., 2013).

It is currently impossible to provide an accurate earthquake forecast (Kanamori, Hauksson, \& Heaton, 1997). However, also a few seconds of early warning time for different vital facilities will be beneficial for pre-programmed disaster actions. For earthquakes that occur spontaneously without precursors and are the most challenging process for prediction. Because of that, designed systems produce so-called shake maps, which graphically illustrate measured ground vibrations immediately after an event to establish and organize emergency measures in areas in need of help (Gasparini \& Manfredi, 2014). In Taiwan, an earthquake early warning system has been created thanks to the Central Weather Bureau's installation of a real-time strong-motion network (Hsiao, Wu, Shin, Zhao, \& Teng, 2009).

Effective Early Warning Systems require improvements in weather warnings (Gunasekera, Plummer, Bannister, \& Anderson-Berry, 2005): Extended warning lead time; enhanced alert quality; the increased need for probabilistic predictions; better communication and distribution; the use of new alerting 
mechanisms; Aiming for suitable and particular customers of warning services (proper, right-of-the-matter information) and notifications and necessary action is understood. There are two concepts, central systems in which the national organization performs these functions and decentralized systems where these tasks are carried out more locally by other agencies, cities, counties, volunteer organizations, and employees in assessing who performs the first two phases of the Early Warning Systems, i.e. monitoring and provision (De León et al., 2006)

There are lot of challenges facing early warning systems: warning communication and community response capabilities; a lack of clear, unambiguous, and precise messages; the use of various channels of communication; the regional understanding of early warning "bottom-up" provides multidimensional sensitivity to issues and requirements through the active participation of surrounding people; and different groups have different priorities; dissemination structures need to be handy to all (old, young, deaf and dumb); schooling of the general public and their recognition need to be improved; understanding of risks and threats; appreciate and synchronization with the extent of preparedness and reaction capacity; unique dangers require unique early caution structures (distinction among drought and tsunami; problems in predicting volcanic eruptions because of insufficiently advanced technical measuring devices; Many structures which are capable of trouble warnings for some of natural hazards are in place; suitable warnings and the capability of the general public to receive, recognize and reply to the issued caution in a well-timed and powerful manner, atmospheric failures are commonly nicely included in international via the countrywide meteorological and hydrological offerings of the World Meteorological Organizations:, whether or not maps and statistics are available, inadequate improvement of countrywide incorporated chance discount and chance control capabilities; the detection of nearby flash foods, prompted through nearby heavy rainfall and the response of small catchments stays a prime challenge.

More systemic, cross-cutting, and applied research is required, including on the following issues (Basher, 2006): improvement and use of geospatial facts models, risk maps and scenarios, cost-powerful observations systems, development of center prediction machine models and prediction equipment, caution choice machine equipment for disaster managers, control under caution uncertainty, assessment and assessment of caution communique methods, fashions of human reaction conduct such as evacuations, visualization of influences and reaction alternatives for network preparedness, etc.

To improve the functioning of early warning systems, it is necessary to meet certain prerequisites regarding the various stages of functioning (Rogers \& Tsirkunov, 2011): 1. monitoring and warning service: institutional mechanisms established; monitoring systems developed; forecasting and warning systems established; 2. dissemination and communication: organizational and decision-making processes institutionalized; effective communication systems and equipment installed; warning messages recognized and understood; 3 . response capacity: warnings respected; disaster preparedness and response plans established; community response capacity assessed and strengthened; public awareness and education enhanced. 


\section{Conclusion}

By identifying different models for early warning systems, the preconditions are created for the development of a comprehensive model that will enhance all the advantages and minimize all the observed disadvantages. Early warning systems and the technology and instruments which enable them to operate best if they are incorporated into the society in which they live, comprehensible, and relevant. To improve these systems, serious political commitment and institutional support are needed for the implementation of innovative solutions and the implementation of further scientific research with the aim of their comprehensive development. In many countries, different systems are used to warn the public of natural hazards and they differ significantly in the degree of their scientific and technological basis and functionality. It is necessary to improve the infrastructure of such systems, raise the level of awareness of the population about the ways of reacting and encourage the implementation of scientific research to develop innovative solutions.

\section{Declarations}

\section{Funding:}

This research was funded by European Union's Horizon 2020 research and innovation program under Grant Agreement No. 740750.

\section{Acknowledgments:}

I would like to thank the Scientific-Professional Society for Disaster Risk Management in Belgrade and International Institute for Disaster Research (http://upravljanje-rizicima.com/), which provided me professional advice throughout the writing and data interpretation.

\section{Competing interests:}

The authors declare no competing interests.

\section{References}

Akhtar, M. K., Corzo, G., van Andel, S., \& Jonoski, A. Rainfall from Satellite Data and Artificial Neural Networks. WaterMill Working Paper Series, 2008, no. 3

Alcántara-Ayala, I., \& Oliver-Smith, A. (2019). Early warning systems: lost in translation or late by definition? A FORIN approach. International Journal of Disaster Risk Science, 10(3), 317-331.

Alfieri, L., Salamon, P., Pappenberger, F., Wetterhall, F., \& Thielen, J. (2012). Operational early warning systems for water-related hazards in Europe. Environmental Science \& Policy, 21, 35-49. 
Alias, N. E., Salim, N. A., Taib, S. M., Mohd Yusof, M. B., Saari, R., Adli Ramli, M. W., Ismail, N. (2020). Community responses on effective flood dissemination warnings-A case study of the December 2014 Kelantan Flood, Malaysia. Journal of flood risk management, 13, e12552.

Aloudat, A., \& Michael, K. (2011). Toward the regulation of ubiquitous mobile government: a case study on location-based emergency services in Australia. Electronic Commerce Research, 11(1), 31-74.

Artan, G. A., Restrepo, M., Asante, K., \& Verdin, J. (2002). A flood early warning system for Southern Africa. In Proc., Pecora 15 and Land Satellite Information 4th Conf.

Ayzel, G., Varentsova, N., Erina, O., Sokolov, D., Kurochkina, L., \& Moreydo, V. (2019). OpenForecast: The First Open-Source Operational Runoff Forecasting System in Russia. Water, 11(8), 1546.

Basher, R. (2006). Global early warning systems for natural hazards: systematic and people-centred. Philosophical transactions of the royal society a: mathematical, physical and engineering sciences, 364(1845), 2167-2182.

Buan, S., \& Diamond, L. (2012). Multi-hazard early warning system of the United States National Weather Service. In Institutional Partnerships in Multi-Hazard Early Warning Systems (pp. 115-157): Springer.

Bubar, A., Eckstein, B., Ell, A., Hilts, E., Martin, S., Powell, T., Rios Rincon, A. (2020). Emergency siren detection technology and hearing impairment: a systematized literature review. Disability and Rehabilitation: Assistive Technology, 1-9.

Chakma, U., Hossain, A., Islam, K., Hasnat, G. T., \& Kabir, M. H. (2021). Water crisis and adaptation strategies by tribal community: A case study in Baghaichari Upazila of Rangamati District in Bangladesh. International Journal of Disaster Risk Management, 2(2), 37-46.

https://doi.org/10.18485/ijdrm.2020.2.2.3

Chen, A., Zhu, H., Ni, X., \& Su, G. (2020). Pre-warning information dissemination models of different media under emergencies. Chinese Physics B, 29(9), 094302.

Cvetković, V. (2020). Disaster risk management (Upravljanje rizicima u vanrednim situacijama). Beograd: Naučno-stručno društvo za upravljanje rizicima u vanrednim situacijama.

Cvetkovic, V. M., \& Martinović, J. (2020). Innovative solutions for flood risk management. International Journal of Disaster Risk Management, 2(2), 71-100.

Cvetković, V. M., Nikolić, N., Radovanović Nenadić, U., Öcal, A., K Noji, E., \& Zečević, M. (2020). Preparedness and preventive behaviors for a pandemic disaster caused by COVID-19 in Serbia. International journal of environmental research and public health, 17(11), 4124.

De León, J. C. V., Bogardi, J., Dannenmann, S., \& Basher, R. (2006). Early warning systems in the context of disaster risk management. Entwicklung and Ländlicher Raum, 2, 23-25. 
Fakhruddin, S. H. M., \& Chivakidakarn, Y. (2014). A case study for early warning and disaster management in Thailand. International journal of disaster risk reduction, 9, 159-180.

Farid, M. M., Prawito, Susila, I. P., \& Yuniarto, A. (2017). Design of early warning system for nuclear preparedness case study at Serpong.

Fearnley, C. J., \& Dixon, D. (2020). Early warning systems for pandemics: Lessons learned from natural hazards. International journal of disaster risk reduction, 49, 101674.

Fujita, K., \& Shaw, R. (2019). Preparing International Joint Project: use of Japanese flood hazard map in Bangladesh. International Journal of Disaster Risk Management, 1(1), 62-80.

Gasparini, P., \& Manfredi, G. (2014). Development of earthquake early warning systems in the European Union. In Early warning for geological disasters (pp. 89-101): Springer.

Gijsbers, P. (2010). Opportunities and limitations of DelftFEWS as a scientific workflow tool for environmental modelling. International Environmental Modelling and Software Society (iEMSs).

Glantz, M. H. (2003, October). Usable science 8: early warning systems: do's and don'ts. In Report of workshop (pp. 20-23).

Goltz, J. D., \& Roeloffs, E. (2020). Imminent Warning Communication: Earthquake Early Warning and Short-Term Forecasting in Japan and the US. In Disaster Risk Communication (pp. 121-153): Springer.

Gouldby, B., Krzhizhanovskaya, V., \& Simm, J. (2010). Multiscale modelling in real-time flood forecasting systems: From sand grain to dike failure and inundation. Procedia Computer Science, 1(1), 809.

Grasso, V. F., \& Singh, A. (2011). Early warning systems: State-of-art analysis and future directions. Draft report, UNEP, 1.

Gunasekera, D., Plummer, N., Bannister, T., \& Anderson-Berry, L. (2005). Natural disaster mitigation: role and value of warnings. Economic value of fire weather services, 3.

Guo, X., \& Kapucu, N. (2019). Examining stakeholder participation in social stability risk assessment for mega projects using network analysis. International Journal of Disaster Risk Management, 1(1), 1-31.

Hsiao, N. C., Wu, Y. M., Shin, T. C., Zhao, L., \& Teng, T. L. (2009). Development of earthquake early warning system in Taiwan. Geophysical research letters, 36(5).

Indrasari, W., Iswanto, B. H., \& Andayani, M. (2018 2018). Early Warning System of Flood Disaster Based on Ultrasonic Sensors and Wireless Technology.

Intrieri, E., Gigli, G., Mugnai, F., Fanti, R., \& Casagli, N. (2012). Design and implementation of a landslide early warning system. Engineering Geology, 147, 124-136. 
Kanamori, H., Hauksson, E., \& Heaton, T. (1997). Real-time seismology and earthquake hazard mitigation. Nature, 390(6659), 461-464.

Khankeh, H. R., Hosseini, S. H., Farrokhi, M., Hosseini, M. A., \& Amanat, N. (2019). Early warning system models and components in emergency and disaster: a systematic literature review protocol. Systematic reviews, $8(1), 1-4$.

Kim, J. J., \& Guha-Sapir, D. (2012). Famines in Africa: is early warning early enough? Global health action, $5(1), 18481$.

Klafft, M., \& Ziegler, H. G. (2014, April). A concept and prototype for the integration of multi-channel disaster alert systems. In Proceedings of the 7th Euro American Conference on Telematics and Information Systems (pp. 1-4).

Krzhizhanovskaya, V. V., Shirshov, G. S., Melnikova, N. B., Belleman, R. G., Rusadi, F. I., Broekhuijsen, B. J., Bubak, M. (2011). Flood early warning system: design, implementation and computational modules. Procedia Computer Science, 4, 106-115.

Kuligowski, E. D., Kuligowski, E. D., \& Doermann, J. (2018). A review of public response to short message alerts under imminent threat. US Department of Commerce, National Institute of Standards and Technology.

Kull, D., Mechler, R., \& Hochrainer-Stigler, S. (2013). Probabilistic cost-benefit analysis of disaster risk management in a development context. Disasters, 37(3), 374-400.

LaBrecque, J., Rundle, J. B., \& Bawden, G. W. (2019). Global navigation satellite system enhancement for tsunami early warning systems. Global Assessment Report on Disaster Risk Reduction.

Legg, T. P., \& Mylne, K. R. (2004). Early warnings of severe weather from ensemble forecast information. Weather and Forecasting, 19(5), 891-906.

Mechler, R. (2016). Reviewing estimates of the economic efficiency of disaster risk management: opportunities and limitations of using risk-based cost-benefit analysis. Natural Hazards, 81(3), 21212147.

Medina-Cetina, Z., \& Nadim, F. (2008). Stochastic design of an early warning system. Georisk, 2(4), 223236.

Mills, A., Chen, R., Lee, J., \& Raghav Rao, H. (2009). Web 2.0 emergency applications: How useful can Twitter be for emergency response? Journal of Information Privacy and Security, 5(3), 3-26.

Morris, A., Kortenhaus, A., \& Visser, P. J. (2009). Modelling breach initiation and growth. Executive summary. 
Ocal, A. (2019). Natural disasters in Turkey: Social and economic perspective. International Journal of Disaster Risk Management, 1(1), 51-61.

Öcal, A., Cvetković, V. M., Baytiyeh, H., Tedim, F. M. S., \& Zečević, M. (2020). Public reactions to the disaster COVID-19: a comparative study in Italy, Lebanon, Portugal, and Serbia. Geomatics, Natural Hazards and Risk, 11(1), 1864-1885.

Osanai, N., Shimizu, T., Kuramoto, K., Kojima, S., \& Noro, T. (2010). Japanese early-warning for debris flows and slope failures using rainfall indices with Radial Basis Function Network. Landslides, 7(3), 325338.

Paleologue, A. (2005, May). Early warning satellites in Russia: What past, what state today, what future?. In Modeling, Simulation, and Verification of Space-based Systems II (Vol. 5799, pp. 146-157). International Society for Optics and Photonics.

Pengel, B. E., Krzhizhanovskaya, V. V., Melnikova, N. B., Shirshov, G. S., Koelewijn, A. R., Pyayt, A. L., \& Mokhov, II. (2013). Flood early warning system: sensors and internet. IAHS Red Book, 357, 445-453.

Perera, C., Jayasooriya, D., Jayasiri, G., Randil, C., Bandara, C., Siriwardana, C., Kamalrathne, T. (2020). Evaluation of gaps in early warning mechanisms and evacuation procedures for coastal communities in Sri Lanka. International journal of disaster resilience in the built environment.

Piciullo, L., Calvello, M., \& Cepeda, J. M. (2018). Territorial early warning systems for rainfall-induced landslides. Earth-Science Reviews, 179, 228-247.

Podvig, P. (2002). History and the current status of the Russian early-warning system. Science and global security, 10(1), 21-60.

Rai, R. K., van den Homberg, M. J. C., Ghimire, G. P., \& McQuistan, C. (2020). Cost-benefit analysis of flood early warning system in the Karnali River Basin of Nepal. International journal of disaster risk reduction, $47,101534$.

Rogers, D., \& Tsirkunov, V. (2011). Implementing hazard early warning systems. Global Facility for Disaster Reduction and Recovery, 11, 1-47.

Rudloff, A., Lauterjung, J., Münch, U., \& Tinti, S. (2009). Preface" The GITEWS Project (German-Indonesian Tsunami Early Warning System)". Natural Hazards and Earth System Sciences, 9(4), 1381-1382.

Sättele, M. (2015). Quantifying the reliability and effectiveness of early warning systems for natural hazards (Doctoral dissertation, Technische Universität München).

Sättele, M., Bründl, M., \& Straub, D. (2016). Quantifying the effectiveness of early warning systems for natural hazards. Natural Hazards and Earth System Sciences, 16(1), 149-166. 
Sharma, B. N., Jokhan, A. D., Kumar, R., Finiasi, R. W., Chand, S., \& Rao, V. (2015). Use of short message service for learning and student support in the Pacific region. In: Springer.

SKYE (2013). Hydrological observations, Finnish Environment Institute, URL http://www. environment.fi/en-US/Maps_and_statistics/Hydrological_observations, last accessed: 2013

Sorensen, J. H. (2000). Hazard warning systems: Review of 20 years of progress. Natural Hazards Review, 1(2), 119-125.

Tang, X. and Y, Zou, 2009: Overview of Shanghai MHEWS and the Role of NMHS. Second Experts' Symposium on MHEWSs with focus on the Role of NMHSs, 5-7 May 2009, Toulouse, France. http://www.wmo.int/pages/prog/drr/events/MHEWSI/Presentations/Session\%201/Shanghai/ShanghaiMHEWS.pdf

Thennavan, E., Ganapathy, G., Chandrasekaran, S., \& Rajawat, A. (2020). Probabilistic rainfall thresholds for shallow landslides initiation - A case study from The Nilgiris district, Western Ghats, India. International Journal of Disaster Risk Management, 2(1), 1-14.

Thomalla, F., \& Larsen, R. K. (2010). Resilience in the context of tsunami early warning systems and community disaster preparedness in the Indian Ocean region. Environmental Hazards, 9(3), 249-265.

Tiranti, D., \& Rabuffetti, D. (2010). Estimation of rainfall thresholds triggering shallow landslides for an operational warning system implementation. Landslides, 7(4), 471-481.

Toya, H., \& Skidmore, M. (2018). Cellular telephones and natural disaster vulnerability. Sustainability, 10(9), 2970.

UNISDR (2012). Terminology. UNISDR (United Nations International Strategy for Disaster Risk Reduction, 2004), Geneva. Available from: http://www.unisdr.org/we/inform/terminology. Accessed 23 July 2021.

UNISDR (United Nations International Strategy for Disaster Reduction) (2005). Hyogo framework for action 2005-2015: Building the resilience of nations and communities to disasters. Available from: https://www.unisdr.org/files/1037_hyogoframeworkforactionenglish.pdf Accessed 23 July 2021.

Villagrán de León, J. C., Pruessner, I., \& Breedlove, H. (2013). Alert and warning frameworks in the context of early warning systems.

Yang, J., Zhang, H., Wang, C., \& Tang, D. (2018). Research on disaster early warning and disaster relief integrated service system based on block data theory. International Archives of the Photogrammetry, Remote Sensing and Spatial Information Sciences, 42, 3. 